goal is to entice us to play the game, perhaps while attending a Reacting summer conference.

While scholarly essays typically conclude that we need more research, this one ends on a different point: we need more thoughtful teaching, accompanied by insightful reflection and writing about our purposes and processes, and richer accounts of what we and our students have learned. Our current lack of a shared vocabulary on teaching and learning should not surprise anyone in academia, where our institutional and individual priorities tend to focus on the number of publications we produce, not the depth of student engagement in our classrooms. But this absence should bother historians of education. Given that we specialize in the dynamics of schooling, and pay close attention to the meanings of words, we still seem uncomfortably challenged, as a profession, when asked to describe how teaching and learning actually happens in our classrooms. No doubt, it is uncommon to be asked by an academic journal to thoughtfully describe our own pedagogy, and to subject these words to close review from our peers. Historians of education simply need more practice. We should improve how we document and describe learning in our own classrooms. Perhaps, we need to take some lessons from ethnographers.

\title{
Case Study as Common Text: Collaborating in and Broadening the Reach of History of Education
}

\author{
Ansley T. Erickson
}

Course: Harlem Stories courses, within the Educating Harlem project

Institution: Teachers College, Columbia University

A graduate school of education contains a wide range of disciplinary models for the training of scholars and practitioners. I encounter these models as they come up in conversation with colleagues and students,

Ansley T. Erickson is Assistant Professor, History and Education, Teachers College, Columbia University (erickson@tc.columbia.edu). She is the author of Making the Unequal Metropolis: Scbool Desegregation and Its Limits (Chicago: University of Chicago Press, 2016). Thanks to the Institute for Urban and Minority Education, the Columbia Center for Digital Research and Scholarship, and TC Provost Tom James for support of Educating Harlem. 
or I confront them more directly as I pass a clinical psychology laboratory space each morning on the way to my office. I often see small groups of doctoral students at work, huddled around a computer monitor or deep in discussion. As my psychology colleagues are more likely to research and write in teams rather than individually, I read this scene as a sign of collaboration built into graduate training. It also contrasts with my experience of collaboration, or the lack thereof, in my own graduate training in history. In my own education, the most collaborative spaces-in which people come together around a common text and problem-existed in the earliest phases of graduate school. A few students and a professor gathered around a seminar table to analyze a book or article. But later, as students developed their own research agendas and proceeded into the archives, they researched and wrote largely in isolation. Writing groups and other venues for sharing work were sustaining, but the content of research remained an individual affair. (There were hints, though, of new spaces for collaboration-as in the History of Education Society's research mentoring sessions begun in 2009-and likely others existed, but were unknown to me as a graduate student.) Once in a faculty position, reflecting on my graduate training and juxtaposed with what I perceived at the psychology laboratory led me to ask where collaboration fits and how it might matter in graduate training in the history of education.

Simultaneously, like many scholars, I have been seeking ways to integrate my research and my teaching. Over the last three years, colleague Ernest Morrell and I developed the Educating Harlem project to build a robust history of education in this storied American community. ${ }^{1}$ We organized a lecture series on campus, convened two scholarly working conferences, and are proposing an essay collection. We also partner with Columbia's Center for Digital Research and Scholarship to create a digital resource related to our work. While not every research endeavor is conducive to collaboration or graduate student involvement, here there were opportunities to ensure that interested students could connect and contribute to the intellectual community developing in the project. I also was thinking pragmatically; when I link my teaching and my scholarship, time and effort invested in one supports the other.

Out of the combination of my interest in collaboration and the Educating Harlem project came a pair of courses built around collective investigation into a single case study: the history of education in twentieth-century Harlem. Teaching these courses, and then reflecting and revising to teach them again, surfaced four lessons about case studies.

'See "Educating Harlem," http://researchblogs.cul.columbia.edu/educatingharlem. 
First, the case study helped facilitate a collaborative research ethos unlike my previous experiences as a faculty member or graduate student. The case study became a common text, terrain for rich shared discussion and learning.

Second, I revised what I meant by a case study. Narrower was better-here, a single school rather than a whole community or neighborhood. Narrowness facilitated deeper collaborative work and enabled deeper engagement with individual stories of people in their full humanity.

Third, I saw the power of the detailed case in challenging broad stereotypes (of race, class, or educational level) often applied to communities such as Harlem by students, historians, or educators. Listening collectively to the voices of past Harlem educators, residents, and students helps destabilize these stereotypes.

And finally, the collaborative case study provided a way to open processes of historical inquiry to students in teacher education and other graduate programs. Taken together, these lessons pushed me to see collaborative inquiry into a selected historical case as a useful medium through which to broaden access to the history of education and, perhaps, to start to strengthen the place of history in graduate schools of education.

\section{Harlem Stories: The Courses as Initially Designed}

Each semester of the Harlem Stories course sequence had three elements. ${ }^{2}$ In practice, these were interwoven, but it is easiest to speak of them as distinct elements. We read existing scholarship on the history of education in Harlem; we engaged in original research (with archival sources in one semester and oral history in the other); and we digitally displayed the products of our research. ${ }^{3}$ About half of the graduate students came from my home program in History and Education; the others came from Teachers College pre- and in-service teacher

${ }^{2}$ Initially taught as Harlem Digital Research Collaborative, I regularized the class as Harlem Stories. The courses are cumulative to a degree, but students can choose to take one or both semesters. This flexibility is important for drawing students from other programs, especially in teacher education, where students often have limited space for elective offerings.

${ }^{3}$ We used the Omeka platform, http://www.omeka.org/, with the Neatline mapping plugin, http://www.neatline.org/. Space limits prevent a full discussion, but it is worth noting that the case-study structure opens opportunities for digitally sharing historical research. Also, the potential for student work to be publicly visible on the Internet raised the stakes of our collaborative work. It strengthened a sense of collective need to make ethical choices, and it moved questions of audience, interpretive authority, and voice from the abstract to the concrete. For examples of student work, see http://educatingharlem.cdrs.columbia.edu/omeka. 
education and other programs in social studies education, curriculum, and technology.

Before the course began, I wanted to provide an experience that would shift students' attention away from what might be their previous (at times stereotyping) views of Harlem to more nuanced and varied human experiences of the place. This concern matters particularly because, although I work to recruit a diverse student population for the class, most of my students come to the study of Harlem (or African American history more broadly) across various forms of social distance. Like the population of Teachers College, many are white students, many are from middle-class or wealthy backgrounds, and all see a present-day Harlem undergoing massive change and gentrification. As a white scholar, I wanted to quickly show that the course would directly address problems of identity and power in historical practice, and that my role was to facilitate collaborative knowledge-making rather than present myself as the expert. I decided to have students hear the voices of Harlem residents before my own. In advance of our first meeting, I asked each student to read at least one of a set of accounts of growing up in Harlem. ${ }^{4}$

In our first session, we discussed how authors understood and assigned meaning to Harlem; at times, comments juxtaposed students' preconceptions with the texts' accounts. I thought of this experience as a preface to ongoing conversations in the course about a core challenge of history: understanding people different than yourself. Historians always face this difference in terms of time, but often in terms of identity and power as well. Just as this is an ongoing challenge in our work, my efforts to address it in my teaching and research remain works in progress.)

After this preface, as in many graduate seminars, we turned to critical discussion of selections from the existing literature. Our practice of careful reading and examination of historical scholarship had an added impetus, knowing that we would be conducting our own research as well. In the course that involved oral history, I chose readings that introduced students to Harlem's educational history and drew on oral testimony. We learned from Barbara Ransby about Ella Baker's Harlem organizing, from Martha Biondi about student activism at the "University of Harlem," and from Gerald Markowitz and David Rosner about

${ }^{4} J a m e s$ Baldwin, Go Tell It On the Mountain (New York: Dial Press, 1963); James Baldwin, The Fire Next Time (New York: Dial Press, 1963); Walter Dean Myers, Bad Boy: $A$ Memoir (New York: HarperCollins, 2001); and Claude Brown, Mancbild in the Promised Land (New York: Macmillan, 1965); assigned alongside a critical essay from Carlo Rotella, October Cities: The Redevelopment of Urban Literature [Berkeley, CA: University of California Press, 1998], 269-92). 
Kenneth Clark's Northside Center. ${ }^{5}$ We paid particular attention to how these authors found, gathered, and deployed oral histories as evidence. Where possible, we used the transcripts of interviews that had been collected in the writing of these books as examples while preparing to conduct our own interviews. ${ }^{6}$ Linking historiographical discussion and methodological considerations around a single case made both more robust, as students noted in final evaluations. Students came to the course with different degrees of historical background on the history of education and U.S. history more generally, yet the shared case study and the hybrid discussion provided points of entry for broad participation.

As we prepared to work with original sources, whether oral histories or archival material, we read key texts on those methods and discussed them in relationship to our study of Harlem. On oral history, we read a variety of texts that helped us think about oral history method, and our discussion of these foregrounded the impact of various forms of social difference-age, education, race, gender, class, and language - on the process of making an oral history. ${ }^{7}$

Addressing the archival record, its limits and silences, has distinct meaning in this particular case as well. In Harlem, archiving has been both a conscious political intervention, as demonstrated by the work of Arturo Schomburg and the Schomburg Center for Research in Black Culture, and yet the archival record remains strikingly incomplete when it comes to questions about the lives of young people in Harlem or the daily experience of schooling there. Materials from the Columbia Rare Book and Manuscript Library raised questions about institutional power and its implications for what is archived. Again, the shared content of the course enhanced our discussion of basic aspects of historical practice.

Our case study investigation into the history of education in twentieth-century Harlem did not start out with a fixed set of research questions, but over the weeks of the course in each semester a few

\footnotetext{
${ }^{5}$ Barbara Ransby, Ella Baker and the Black Freedom Movement: A Radical Democratic Vision (Chapel Hill, NC: University of North Carolina Press, 2005); Martha Biondi, The Black Revolution on Campus (Berkeley, CA: University of California Press, 2012); and Gerald E. Markowitz and David Rosner, Children, Race, and Power: Kenneth and Mamie Clark's Nortbside Center (New York: Routledge, 2000).

${ }^{6}$ For oral histories from Markowitz and Rosner's research, see the Columbia Center for Oral History, http://library.columbia.edu/locations/ccoh.html.

${ }^{7}$ On oral history method, see Robert Perks and Alistair Thomson, Tbe Oral History Reader (New York: Routledge, 2006). On archives, see Terry Cook and Joan M. Schwartz, "Archives, Records, and Power: From (postmodern) theory to (archival) performance," Arcbival Science 2, no. 1-2 (2002), 171-85; Ann Laura Stoler, "Colonial Archives and the Arts of Governance," Arcbival Science 2, no. 1-2 (2002), 87-109; and Kate Theimer, "Archives in Context and as Context," Fournal of Digital Humanities 1, no. 2 (Spring 2012), http://journalofdigitalhumanities.org/1-2/archives-in-context-and-ascontext-by-kate-theimer/.
} 
key areas of investigation emerged. We were consistently engaged with activism - what forms it took, in whose hands, and toward what visions of education. We also noticed which voices were most frequently heard or most frequently absent (children themselves).

Even as these areas of interest emerged, it proved generative to approach primary source material in a more exploratory fashion. This let sources generate new questions rather than being seen through the lens of relevance, or irrelevance, for an individual project. Rather than explaining how a document answered a particular question, describing a document or assigning keyword tags (activities made necessary by our plans to create digital exhibits) prompted all of us to slow down and make space for wonder and serendipity in the research process. We became curious about documents in relationship to others, and to the archives in which they sat. Choices about description and tagging offered concrete examples of how archival practices shape knowledge. Similarly, conversations about single documents illustrated how differently individuals could see a common text, and how the same document held different value for different readers. One student dismissed as uninteresting the lists of names and addresses in a folder she was examining; for another student, these same lists provided a window into where teachers lived in relationship to their schools and students.

Here, it is important to note how a course likes this, engaging case study and method together, fits within graduate history education. A historical practicum cannot replace a broader or more theoryintensive introduction to historiography and historical method. Instead, for historians in training, this course may offer a bridge between a methodological introduction and individual archival research and writing. And for students who are not training as historians and are less likely to have access to such a methods course, the practicum offers an accessible introduction to the discipline via its grounding in a common case. $^{8}$

Although graduate students in history will proceed in individual dissertation research projects, most unrelated to Harlem, I hope the experience of a collaborative research endeavor expands their sense of how historical research can be done, how multiple perspectives can inform their work in progress, and how encounters with historical documents can prompt shifts in, or even wholly new, research questions.

The case study proved to have distinct value for future $\mathrm{K}-12$ teachers as well. It offered them firsthand experience with the uncertainty and the complexity of historical interpretation. Despite the good efforts of history education scholars such as Sam Wineburg to break open

\footnotetext{
${ }^{8}$ For more on this latter point, see Heather Lewis's essay in this forum.
} 
the craft of historical thinking, too much of history appears in $\mathrm{K}-12$ curricula as polished, undebated fact. ${ }^{9}$ Experiencing the shared critique of historical writing, as well as the struggles of interpretive judgment, offers future educators a different vision of the discipline. Although historians in training and future teachers came to the course from different perspectives, the case study became a common text for collaboration of value to both.

\section{Harlem Stories: Reflections and Revisions}

Having taught the Harlem Stories courses over two semesters, I began to make adjustments to further capitalize on the case study as a common text. In the oral-history focused course, where earlier students had conducted individual interviews, I added an interview that we could experience as a group. Responding to students who felt, understandably, nervous about conducting their own interviews, I conducted one oral history interview in a "fishbowl" style. Students observed for most of the session, and participated with questions toward the end. ${ }^{10}$ That interview provided one of the richest experiences of the course, as students reflected upon and critiqued the choices I made as an interviewer and upon the challenging content of the interview. We shared a common base of knowledge about the time and place our interviewee narrated, and we heard the interview in this context. ${ }^{11}$

The shared interview experience prompted me to take stock of how frequently, in earlier iterations of the course, we had deeply investigated a common text. In the semester focused on archival research, we examined portions of three manuscript collections with some bearing on education in 1960s Harlem. Despite this commonality, students rarely read and discussed the same document in the same depth that we had discussed the common interview because of how I had designed student interaction with the archival material. ${ }^{12}$ This reflection prompted me to consider how I had defined my "case." We looked at material related to the history of education in Harlem, but that was, in fact, quite a broad topic, even when narrowed to a few decades. The materials took us in

\footnotetext{
"Sam Wineburg, Historical Thinking and Otber Unnatural Acts: Charting the Future of Teacbing the Past (Philadelphia, PA: Temple University Press, 2001).

${ }^{10}$ Recognizing that this would be a challenging setting for the interviewee, $I$ invited a participant who was an experienced public speaker and who expressed confidence that he had stories that needed to be recorded.

"For another example, see Laura Browder and Patricia Herrera, "Civil Rights and Education in Richmond, Virginia: A Documentary Theater Project," Transformations: The 7ournal of Inclusive Scholarsbip and Pedagogy 23, no. 1 (Spring 2012), 15-36, 158-59.

${ }^{12}$ We worked with material from three collections: Annie Stein Papers and Union Settlement Association Papers, Columbia Rare Book and Manuscript Library, and Morningside Area Alliance, Columbia University Archives.
} 
as many divergent as convergent directions. Whole-class discussions lacked the depth I had seen around the shared interview.

In part due to this observation, I have decided to define the case even more narrowly in the next iterations of the course. Rather than taking the history of education as a case, we will take on a topic of microhistorical scale: the story of a single school, Wadleigh High School, which operated in Harlem in various forms from 1902 to the present. ${ }^{13}$ It offers a microcosm of the community's educational history. Our initial readings give structural, institutional, and neighborhood context for Wadleigh's story, and our archival and oral history work will center on the school. My pedagogical hope is that our narrower case will encourage deeper discussion and collaboration, and that Wadleigh as a case will be an even richer common text for sustained inquiry.

Another area of gradual revision has been around identity in oral history interviewing. Previous interviews have become texts to examine how differences or similarities in identity between interviewer and interviewee matter in oral history, enriching this discussion. Some oral histories have been conducted by pairs of interviewers of different backgrounds, a practice we will continue to explore. Without seeking a singular model, the goal is to practice oral history (and history more generally) with attention to the potential and limitations of both similarity and diversity of identity in research, while prioritizing respectful care for our interview participants and the stories they want to convey.

\section{Purposes for a Collaborative Case Study}

As I continue to teach the Harlem Stories classes, I am curious to see what, if any, impact they have on the research trajectory of the future historians who participate. In the short term, it is clear that the case study offers a rich basis to create a collaborative research ethos. For future teachers and students from outside of history, the narrow focus helps make the dynamics of historical research more visible and accessible.

Yet I see another, more general, purpose in the case study. The course asks graduate students in history and education to hear a former Harlem teacher describe his school and his students, or to track, as we will in the 2015-2016 year, the many ways Harlem junior high schoolers represented their school and their community in their yearbooks.

${ }^{13} \mathrm{~A}$ collection of materials from Wadleigh are held at the Schomburg Center for Research in Black Culture, a research unit of the New York Public Library system, and the school has an organized alumni network. 
Doing so has value well beyond the particular training needed by historians or teachers. Taking a community seriously beyond stereotype and generalization, reckoning with what a community has said about itself and its schools, pushes future teachers and historians to conceive of their work in terms broader than filling in historiographical gaps or crafting lesson plans. These experiences serve as reminders to listen. They push students not to complacently accept the categorizations and labels so easily, and often falsely, applied to urban and black communities, but instead to listen to those communities and their representations of their own stories. These reminders helped future teachers in the course identify the need to get to know the communities in which they would be teaching. And these reminders to listen, attached not to abstract historical actors but to particular voices encountered in interviews and in the archive, brought the ethically weighty work of historical representation to the forefront of future historians' thinking. With these conversations in mind, I look forward to further collaboration on the history of education in Harlem.

\section{Future Teachers and Historical Habits of Mind: A Pedagogical Case Study}

\section{Heatber Lewis}

\section{Course: Roots of Urban Education (graduate course in teacher education)}

Institution: Pratt Institute, Brooklyn, New York

For the past ten years, I have taught the Roots of Urban Education, a graduate-level course for preservice art teachers and librarians, and have used the course as a pedagogical case study to help improve my teaching. Given that this is the only history course students in the teacher education program are required to take, the course emphasizes depth over breadth through a place-based study of schooling during key reform eras in twentieth-century New York City. I documented, analyzed, and revised my teaching, with special focus on my expectation

Heather Lewis is professor and acting chair of Art and Design Education at Pratt Institute. Lewis's historical research explores the intersection of urban social movements and institutional reform. She also conducts research on teaching, learning and assessment. She thanks her current and former students for their critical and creative feedback. 